DOI: $10.5455 / 2320-1770$. ijrcog20130936

\title{
Sirenomelia: a case report with literature review
}

\section{Latika Sahu*, Sunita Singh, Gauri Gandhi, Krishna Agarwal}

Department of Obstetrics \& Gynecology, Maulana Azad Medical College and associated Lok Nayak Hospital, New Delhi, India

Received: 5 May 2013

Accepted: 25 May 2013

\section{*Correspondence:}

Dr. Latika Sahu,

E-mail: latikasahu@gmail.com

(C) 2013 Sahu L et al. This is an open-access article distributed under the terms of the Creative Commons Attribution Non-Commercial License, which permits unrestricted non-commercial use, distribution, and reproduction in any medium, provided the original work is properly cited.

\begin{abstract}
We are presenting a case of Sirenomelia (Mermaid Syndrome), which is an extreme example of the caudal regression syndrome. It invariably presents with lower limb fusion, sacral and pelvic bony anomalies, absent external genitalia, imperforate anus, and renal agenesis or dysgenesis. There are approximately 300 cases reported in the literature, 15\% of which are associated with twinning, most often monozygotic. The syndrome of caudal regression is thought to be the result of injury to the caudal mesoderm early in gestation. The case encountered was a stillborn baby.
\end{abstract}

Keywords: Sirenomelia, Mermaid syndrome, Caudal regression syndrome

\section{INTRODUCTION}

Sirenomelia is a rare congenital malformation consists of varying degrees of lower limb fusion, appears like a mermaid's tail. Sirenomelia has an incidence of 0.8 to 1 case per 1,00,000 births. ${ }^{1}$ This is usually fetal within a day or two of birth because of complications associated with abnormal kidney and urinary bladder development and function. ${ }^{2}$ It is more common in fetuses of diabetic mothers and monozygotic twins. It invariably presents with lower limb fusion, sacral and pelvic bony anomalies, absent external genitalia, and renal agenesis or dysgenesis. ${ }^{3}$ More than half the cases of sirenomelia result in stillbirth and this condition is 100 times more likely to occur in identical twins than in single births or fraternal twins. ${ }^{4}$

\section{CASE REPORT}

A 28-year-old unbooked primigravida presented to antenatal outpatient department $\left(1^{\text {st }}\right.$ visit $)$ at 34 weeks with history of discharge per vagina since 1 day. There was no prior antenatal checkup or basal ultrasonography. There was no significant medical history. Fundal height was corresponding to 28 weeks and liquor appeared clinically reduced. Her third trimester ultrasound revealed severe growth restriction, oligohydramnios and, absence of bilateral kidneys and fetal bladder. Rest of the anatomy wasn't clear because of very poor visibility.

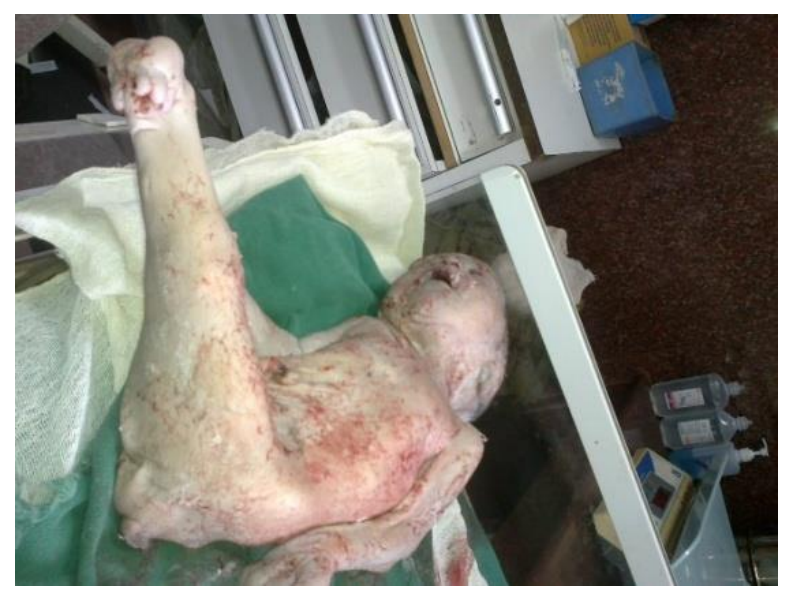

Figure 1: Stillborn baby with sirenomelia.

We explained about the poor prognosis to the patient. She left for spontaneous onset of labor and delivery. At 40 weeks she went into labor spontaneously and delivered a 
$1.64 \mathrm{~kg}$ fresh still born baby with normal upper part of the body, deformed pelvic bones, fused lower limbs into single lower limb, absent external genitalia and imperforate anus, as shown in figure 1. Autopsy was declined. Mother did not have any intrapartum or postpartum complication.

\section{DISCUSSION}

The first medical description of Sirenomelia was by Rocheus and Polfyr way back in the sixteenth century. Duhamel in 1961 defined all the anomalies of mermaid syndrome and described it as the most severe form of caudal regression syndrome. ${ }^{5}$ Sirenomelia is a multisystemic condition with severe malformations of the gastrointestinal, genitourinary, cardiovascular and musculoskeletal systems are usually present. Oligohydramnios secondary to severe renal dysplasia is universal. Male to Female ratio being 3:1, the malformation sequence consists of varying degrees of lower limb fusion bearing a resemblance to the mermaid of ancient Greek mythology ${ }^{6,7}$ Sirenomelia does not recur in families and no chromosomal abnormalities are observed. ${ }^{5}$ The maternal blood glucose levels should be optimal in preconception period and in first trimester.

Around 300 cases reported in the world literature, of which 13 have been from India. ${ }^{5}$ Most of them were diagnosed after birth and no definite antenatal diagnosis was possible in all of these cases. ${ }^{4}$ Our case had suspicion of this anomaly by ultrasonography in antenatal period. The sirenomelia is diagnosed by sonography as early as 9 weeks. Diagnosis is difficult during the second trimester because of the severe oligohydramnios. Prenatal diagnosis is made by the lack of both tibia and or fibula with or without feet or identification of a single femur, a convergent femoral bone that does not change with time. Diagnosis can be confirmed by High-resolution sonography by presence of continuous skin line over both femurs on a transverse scan of the thigh, indicating fused thighs. Color Doppler sonography reveals the origin of the aberrant vitelline artery that continues as the single umbilical artery. All infants with a vitelline umbilical artery will have other malformations, the most common being sirenomelia. Other malformation includes external genitalia which are either absent as in our case or rudimentary, whereas the gonads are usually unaffected. The gastrointestinal anomalies include a blind-ending colon, rectal atresia and imperforate anus. Survival depends on the associated anomalies, especially renal function. Initial treatment includes supportive care and diverting colostomy, later includes a multidisciplinary surgical approach. ${ }^{8}$ Owing to visceral abnormalities, sirenomelia is usually incompatible with life; death occurs in the perinatal period. Recently, a few exceptional cases have survived owing to the presence of a functional kidney and reconstructive surgery to restore pelvic organs and separate the legs. The babies that survived had normal neurological development. ${ }^{9}$
Stocker and Heifetz classified sirenomelia into type I to type VII, according mainly to the presence of skeletal elements in the thigh and leg. In type I, the mildest form, all bones in the two fused limbs are present, and the fusion only affects superficial tissues. In type VII, the most severe form, only a single bone is present, with no indication of legs or feet. ${ }^{10}$

Genesis of the limb phenotype in sirenomelia is due to merging of the two bilateral hind limb buds. Owing to the original position of the leg fields in the lateral body wall, their approximation and subsequent merging would occur if the parts normally lying between them did not develop. Therefore, a failure of midline structures to develop either the cloacal and urogenital sinus at the ventral side, or the somites and neural tube at the dorsal side - can result in the approximation and merging of the hind limb fields. Therefore, and despite the merging of the lower limbs giving the name to the sirenomelia condition, it might be secondary, and occur as a consequence of the approximation of the limb fields.

Experimental data suggest that sirenomelia has a genetic basis resulting from a defect in RA or Bmp signaling in the caudal embryonic region. ${ }^{11}$ Although the primary molecular defect underlying sirenomelia remains unknown, clinical studies have given rise to two main pathogenic hypotheses- these are the vascular steal hypothesis and the defective blastogenesis hypothesis.

The vascular steal hypothesis: proposes that the SUA of vitelline origin diverts blood flow to the placenta, leaving the lower part of the body with a severely deficient circulation and might be favored in the remodeling of the very early capillary plexus if there is a defect in the formation of the caudal part of the aortas. According to the vascular steal hypothesis, fusion of the limbs results from a deficient blood flow and nutrient supply to the caudal mesoderm, which in turn would result in agenesis of midline structures and subsequent abnormal approximation of both lower limb fields. In this view, the variable lower limb phenotype depends on the variable development of the sciatic artery, a branch of the recurved distal portions of the dorsal aorta that initially supplies the leg bud and that, with variable development, is normally present in sirenomelia. Vascular mechanisms have been proposed to underlie the pathogenesis of sirenomelia. $^{12}$

The defective blastogenesis hypothesis: According to the defective blastogenesis hypothesis, sirenomelia is a primary defect of blastogenesis that occurs during the final stages of gastrulation at the tail bud stage, corresponding to the third gestational week in humans. ${ }^{13}$ The phenotypic variability depends on the intensity, time of initiation and duration of the underlying event. Although the vascular steal hypothesis and the deficient blastogenesis hypothesis do not exclude one other, it is reasonable to assume that deficient blastogenesis would concomitantly affect organ and vessel development. 
Genetic aspects of sirenomelia: More recently, a sirenomelia-like phenotype has been observed in several genetically modified mouse strains with either gain-offunction of retinoic acid (RA) signaling or loss-offunction of bone morphogenetic protein (Bmp) signaling.

Bmp signaling in caudal development and vasculogenesis: Bmp signaling performs multiple important roles during early embryogenesis, including the control of gastrulation and plays a crucial role in angiogenesis and vasculogenesis by promoting endothelial cell activation, migration and proliferation, three processes that are central to the establishment and remodeling of the vasculature. Bmp signaling also directs maturation of the primitive capillary plexus into the mature vasculature. ${ }^{14}$

$R A$ signaling in caudal development and vasculogenesis: Similar to Bmp, RA signaling also plays crucial roles during early embryogenesis, particularly in influencing the development of caudal structures. The spatiotemporal distribution of RA in the early embryo is tightly controlled by the balanced expression of its synthesizing and catabolizing enzymes. ${ }^{15}$ The expression of Cyp26al, which occurs at the early gastrula stage in the primitive streak and its newly formed mesoderm, shifts to the open neuropore, hindgut endoderm and tailbud mesoderm at the late gastrula stage, where it participates in the caudal development of the embryo. ${ }^{16}$ Sirenomelia occurs when RA signaling is increased in the caudal end of the embryo. Increasing RA levels act by decreasing Bmp signaling levels. ${ }^{17}$

\section{CONCLUSION}

Patients who present with oligohydramnios along with fetal growth retardation either with or without history of leaking, we should look for fetal kidneys and fetal bladder along with fetal vasculature. Therapeutic abortion can be carried out in earlier gestation due to invariably lethal condition. If diagnosed in later gestation we can avoid cesarean section for fetal indication. Sirenomelia is a rare fatal congenital malformation with severe visceral anomalies that decide the survival. Fusion of the lower limbs is less fatal. Few surviving patients need a multidisciplinary approach of treatment.

\section{REFERENCES}

1. Kallen B, Castilla EE, Lancaster PA, Mutchinick O, Knudsen LB, Martinez-Frias ML, Mastroiacovo P, Robert E: The cyclops and the mermaid: an epidemiological study of two types of rare malformation. J Med Genet 1992;29:30-35.

2. Taori KB, Mitra K, Ghonga NP, Gandhi RO, Mammen T, Sahu J. Sirenomelia sequence (mermaid): report of three cases. Indian J Radiol Imaging 2002;12:399-401.
3. Assimakopoulos E, Athanasiadis A, Zafrakas M, Dragoumis K, Bontis J. Caudal regression syndrome and sirenomelia in only one twin in two diabetic pregnancies. Clin Exp Obstet Gynecol 2004;31:1513.

4. Sammons, Mary Beth (November 26, 2009).10 year old girl born with legs fused together AOL. Archived from the original on November 26, 2009.

5. Duhamel B. From the Mermaid to Anal Imperforation: The Syndrome of Caudal Regression. Arch Dis Child 1961;36:152-5.

6. Martinez-frios ML, Garica A, Bermejo E. Cyclopia and sirenomelia in live infant. J Med Genet 1998;35:263-4.

7. Carbillon L, Seince N, Largillière C, Bucourt M, Uzan M. First-trimester diagnosis of sirenomelia A case report. Fetal Diagn Ther 2001;16:284-8.

8. Thottungal A. D., Charles A. K., Dickinson J. E., Bower C. Caudal dysgenesis and sirenomelia-single centre experience suggests common pathogenic basis. Am J Med Genet 2010;152A:2578-87.

9. Messineo A, Innocenti M, Gelli R, Pancani S, Lo Piccolo R, Martin A. Multidisciplinary surgical approach to a surviving infant with sirenomelia. Pediatrics 2006;118:e220-e223.

10. Stocker JT, Heifetz SA. Sirenomelia. A morphological study of 33 cases and review of the literature. Perspect. Pediatr Pathol 1987;10:7-50.

11. Zakin L, Reversade B, Kuroda H, Lyons KM, De Robertis EM. Sirenomelia in Bmp7 and Tsg compound mutant mice: requirement for Bmp signaling in the development of ventral posterior mesoderm. Development 2005;132:2489-99.

12. Sadler TW, Rasmussen SA. Examining the evidence for vascular pathogenesis of selected birth defects. Am J Med Genet 2010;152A:2426-36.

13. Duesterhoeft SM, Ernst LM, Siebert JR, Kapur RP. Five cases of caudal regression with an aberrant abdominal umbilical artery: further support for a caudal regression-sirenomelia spectrum. Am J Med Genet 2007;143A:3175-84.

14. Garriock RJ, Czeisler C, Ishii Y, Navetta AM, Mikawa T. An anteroposterior wave of vascular inhibitor downregulation signals aortae fusion along the embryonic midline axis. Development 2010;137:3697-706.

15. Duester G. Retinoic acid synthesis and signaling during early organogenesis. Cell 2008;134:921-31.

16. Ribes V, Fraulob V, Petkovich M, Dolle P. The oxidizing enzyme CYP26a1 tightly regulates the availability of retinoic acid in the gastrulating mouse embryo to ensure proper head development and vasculogenesis. Dev Dyn 2007a;236:644-53.

17. Sheng N, Xie Z, Wang C, Bai G, Zhang K, Zhu Q, et al. Retinoic acid regulates bone morphogenic protein signal duration by promoting the degradation of phosphorylated Smad1. Proc Natl Acad Sci USA 2010;107:18886-91.

DOI: $10.5455 / 2320-1770 . i j r \operatorname{cog} 20130936$

Cite this article as: Sahu L, Singh S, Gandhi G, Agarwal K. Sirenomelia: a case report with literature review. Int J Reprod Contracept Obstet Gynecol 2013;2:430-2. 